\title{
El autoconocimiento como asignatura pendiente de la psicología en tanto ciencia humana
}

\section{Self-knowledge as a pending subject of psychology as a human science}

\author{
María Verónica Tello Leyva* \\ Escuela Profesional de Psicología, \\ Universidad de San Martín de Porres, Perú
}

\section{Resumen}

Entrelazar el autoconocimiento con la psicología, supone un análisis sereno y profundo sobre el camino recorrido por la psicología, desde su nacimiento hasta la actualidad; retomando su objetivo original de estudio: el alma humana. Este estudio, se sitúa inexorablemente en la esencia misma de la filosofía; lugar donde se gesta, forma y nace la psicología. Solo a partir de la filosofía y de la inclusión de la psicología en el campo de las ciencias humanas, se entiende el abandono que esta hace de su objeto original de estudio en su anhelo de ser reconocida como ciencia, pero sobre todo, se conocen las fortalezas y debilidades alcanzadas por la psicología contemporánea. Hecho que la coloca en una posición sumamente favorable para transitar, más que ninguna otra ciencia, dentro de los aspectos subjetivos como objetivos de la naturaleza humana, con relación a la máxima extraída del Templo de Delfos, tarea dejada por Sócrates: «conócete a ti mismo y conocerás a los demás». Lo que se plantea, es una nueva visión científica, desde el marco de una renovada psicología filosófica; y a partir de ahí, dar el salto cuántico de la ciencia a la metaciencia. El resultado, en la tarea de concretar la conquista del autoconocimiento, es lograr un punto de encuentro entre la naturaleza física y metafísica del ser humano.

Palabras clave: autoconocimiento, psicología, filosofía, Sócrates, positivismo científico, ciencia, metaciencia.

Este es un artículo Open Access bajo la licencia Creative Commons Atribución-NoComercial-Compartirlgual 4.0

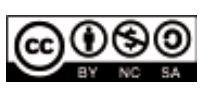




\begin{abstract}
IInterlacing self-knowledge with psychology means to land in the serene and deep analysis on the path traveled by psychology, from its start to the present time, and return to the original objective of study: the human soul. This study places inexorably in the very essence of philosophy, where psychology develops, forms and originates. Only from philosophy and the inclusion of psychology in the field of human sciences, the strengths and weaknesses reached by contemporary psychology, as well as the abandonment of its original object of study, in its will to be recognized as a science, are understood. This fact places psychology in an extremely favorable position to travel, more than any other science, within the subjective and objective aspects of human nature, in relation to what Socrates studied and his thought extracted from the Delphi temple: Know thyself and you will know the others. This article proposes a new scientific vision, from the frame of a renewed philosophical psychology, encouraged to take the quantum leap from science to metascience, resulting in the task of concretizing the conquest of selfknowledge: a meeting point between the physical and metaphysical nature of human beings.
\end{abstract}

Keywords: self-knowledge, psychology, philosophy, Socrates, scientific positivism, science, metascience.

\title{
Introducción
}

Tratar el tema del autoconocimiento como asignatura pendiente de la psicología considerada como ciencia humana, requiere crear un enlace importante e inevitable entre la filosofía y las ciencias humanas. En tanto la psicología, se gesta, nace, crece y se desarrolla originalmente como rama de la filosofía donde su objeto de estudio es claramente determinado en el periodo antropológico de la filosofía clásica occidental, lo cual ha quedado plasmado hasta nuestros días en su definición etimológica.

Relacionar el tema del autoconocimiento con el alma humana, objeto original de estudio de la psicología, hace necesario estudiar este tema 
entrelazando a la psicología con sus raíces profundas; las mismas, que conducen obligatoriamente a reparar en el hecho que no puede haber psicología sin el quehacer filosófico. Son dos materias del conocimiento que se presentan en este caso como indivisas e indisolubles entre sí.

Toda vez que el hombre es por naturaleza un ser eminentemente psicológico y filosófico, ya que el ser humano encierra dentro de sí, como aspecto connatural a sí mismo, el deseo más profundo por conocer, entender, aceptar y proteger al ser que está llamado a vivir dentro de él a lo largo de su existencia, al cual demanda de forma latente en el transcurso de las mismas preguntas de carácter trascendentales, en la medida que estas se encuentran íntimamente ligadas con el sentido de la existencia y, por ende, a la misión existencial del ser humano.

El dar respuesta a la pregunta sobre el sentido de la existencia, formulada desde la perspectiva del ser humano, unida al conocimiento de sí mismo, lleva a considerar los logros alcanzados por la psicología a lo largo de su proceso histórico como ciencia humana, a la luz de los principios de la ciencia y de la fuerza inspiradora de la filosofía. A partir de ello, se aborda el autoconocimiento como asignatura pendiente de la psicología en cuanto ciencia humana, con cara a ir en busca de nuevas alternativas de solución a las demandas del hombre de hoy, frente a la necesidad de salir victorioso en el reto más importante de todos los tiempos. Reto que ha sido planteado por su propia naturaleza desde hace más de 2400 años por intermedio de Sócrates, -uno de los más grandes mentores de la filosofía universal- en el imperativo délfico nosce te ipsum; que demanda conócete a ti mismo.

Lo señalado, solo se puede lograr por medio de una hermenéutica comprometida y actualizada; la misma que deberá conducir a la psicología, gracias a la práctica del contacto directo, con las necesidades del alma humana y a la ruta recorrida por la misma en el campo de la fisiología a retornar enriquecida a la fuente donde esta fue gestada. Entiéndase a la filosofía, madre de todas las ciencias; con el fin de que la filosofía, psicología y ciencia puedan cumplir con el objetivo de entregar al ser humano los medios necesarios para su realización personal mediante el acceso a la autognosis. 


\section{La psicología y filosofía occidental en la ruta del autoconocimiento}

Abordar el tema de la interrelación existente entre filosofía, psicología y autoconocimiento exige replantear el entendimiento sobre estos conceptos. En principio, es importante señalar que el presente estudio se enmarca dentro de la psicología filosófica, conocida también como filosofía metafísica o filosofía racional. Es decir, se alinea con el pensamiento abierto, con el propósito de ofrecer una nueva vía de apertura y con el análisis de un tema pendiente de ser tratado adecuadamente desde hace más de 2400 años.

Es relevante señalar que Sócrates, padre de la Filosofía Universal, dejó una tarea a las generaciones venideras en su máxima extraída del templo de Apolo en Delfos: «Conócete a ti mismo y conocerás a los demás», aquello que constituye, sin lugar a dudas, el aspecto más importante por excelencia, para el desarrollo y acceso a la naturaleza individual del ser humano. Es el autoconocimiento, lo que no ha dejado, ni dejará de situarse, en el centro del corazón del hombre. ${ }^{1}$

En efecto, Sócrates plantea el tema del autoconocimiento dentro del saber filosófico, lo cual es considerado como «la más elevada expresión de la necesidad de saber» (Jolivet, 1956, p. 10).

Es precisamente, aquella elevada expresión de la necesidad del saber que solía experimentar Sócrates dentro de sí, que lo induce a ir en búsqueda del oráculo del templo de Apolo en Delfos para preguntarle icuál es el mayor conocimiento al que un ser humano podría aspirar?, recibiendo como respuesta:

Te advierto quien quiere que fueses, o tú, que desees ondear los arcanos de la naturaleza que, si no hallas dentro de ti mismo aquello que buscas, tampoco podrás hallarlo afuera, si tú ignoras las excelencias de tu propia casa, ¿cómo pretendes encontrar otras excelencias? En ti se halla oculto el tesoro de los tesoros, hombre Conócete a ti mismo y conocerás a Dios y al universo del que formas parte. (como se citó en Martínez, 2014)

Téngase en cuenta que en este artículo los términos hombre y ser humano se emplean como sinónimos de género humano, lo que no excluye al sexo femenino. 
Pausaneas, el célebre turista (siglo II d. C.), en su descripción de Grecia, en el libro X dedicado a la Fócida, capítulo 24, párrafos 1 y 2, relata que en el patio del templo de Apolo en Delfos, estaban inscritas (Plinio dice que con letras de oro) frases de utilidad para la vida de los hombres que conocen todos los griegos, tales como «conócete a ti mismo y nada en demasía». El mensaje dado a Sócrates por parte del oráculo de Apolo contiene, sin lugar a dudas, la fórmula de oro para el ser humano que esté dispuesto a tomarse la vida como la extraordinaria posibilidad de disfrutar de ella, valiéndose de la actitud adecuada en el transcurrir por la misma.

Para ello, es necesario apelar a los recursos que la naturaleza le ha entregado al hombre; empezando por asumirse como un ser privilegiado, responsable y comprometido consigo mismo y con los demás seres de la naturaleza. En razón de poseer aquella capacidad de análisis y reflexión ante todo lo que le rodea, permitiéndose transitar por la vida cuestionándose tanto por los aspectos más elementales, como por los más trascendentales de la existencia. Es indudable que, desde aquel momento hasta la actualidad, transcurrieron muchas generaciones, ideas, iniciativas y esfuerzos, que sin tener conciencia plena de la importancia que implica el resolver y descifrar la fórmula de acceso al autoconocimiento, se han encontrado transitando en la periferia de la ruta que los induzca a la autognosis.

De hecho, ha pasado mucha agua bajo el puente que debemos cruzar para ir al encuentro de nuestra propia identidad mediante el autoconocimiento. Sin embargo, resulta necesario considerar que todo lo que hemos hecho, dejado de hacer y debemos hacer, para acceder a la ansiada conquista de conocernos a nosotros mismos, pasa por hacer un recorrido sereno, abierto y responsable por el camino transitado por la filosofía y la psicología desde sus orígenes hasta nuestros tiempos. No sin antes establecer con claridad lo que debemos entender, cuando nos referimos o empleamos los términos filosofía, psicología y autoconocimiento.

\section{Definición del ser humano desde una perspectiva neohumanista}

En principio, es necesario señalar que tanto la psicología, la filosofía y el tema del autoconocimiento presentan como centro de interés y esfuerzo la realización y bienestar del ser humano. Pero, ¿qué es el ser humano?, en esta 
investigación, frente a tamaña pregunta, se consideran dos principales aspectos: el primero, responde a la visión y definición que se da al ser humano desde la psicología como ciencia humana, mediante la influencia del positivismo científico; el segundo, la definición del ser humano. Efectivamente, el ser humano desde la perspectiva de la psicología contemporánea viene siendo considerado y definido como una unidad psicobiológica, compuesta de cuerpo y alma, o de cuerpo y mente, que para efectos de la psicología como ciencia humana viene a ser lo mismo.

En otras palabras, la ciencia asume alma y mente como sinónimos para determinar su objeto de estudio; a pesar que el término psiquis como prefijo del término psicología determina etimológicamente su objeto de estudio. Al ser la psicología, desde sus orígenes, la rama de la filosofía que se encarga del estudio del alma induce a replantear la necesidad de especificar la diferencia entre alma y mente. De hecho, la postura de las ciencias humanas dada la marcada influencia de sus paradigmas epistemológicos positivistas se encuentra, a diferencia de lo planteado en este estudio, dentro de la práctica del pensamiento cerrado al rechazar todo concepto de carácter metafísico como parte de la naturaleza del hombre; no existe ningún reparo en asumir y tratar al ser humano desde una perspectiva netamente fisiologista.

Lo descrito, para efectos de acceso al autoconocimiento, no solamente resulta totalmente estéril, sino que además representa una barrera que se debe traspasar; toda vez que uno de los principios fundamentales para tener acceso a la autognosis pasa por determinar, de manera clara y precisa, los elementos que conforman la naturaleza humana, así como la función de todos y cada uno de dichos elementos, unidos a la forma como todos ellos se relacionan y actúan entre sí. Con relación a ello y, en concordancia con el carácter teleológico del tema, se presenta al ser humano como una unidad tridimensional, compuesta de cuerpo, alma y espíritu. Con esta afirmación, se pone de manifiesto la urgente necesidad que tiene la psicología de retomar el alma humana como su objeto original de estudio, en cuanto ciencia humana.

$\mathrm{Al}$ respecto, no hacerlo es tener una visión mutilada de la naturaleza humana, en tanto el ser humano existe y se manifiesta solo y por medio de su tridimensionalidad; es decir, ninguno de los tres elementos que conforman su naturaleza pueden existir alejados de los otros dos. En efecto, el ser humano 
no podría ser percibido ni existir en el plano material sin el maravilloso organismo del cuerpo humano, el mismo que cobra vida dada la fuerza vital que le infunde el alma, la misma que adquiere carácter de humana gracias a la naturaleza espiritual del hombre. Es precisamente, en esta última, que se gestan los valores y principios éticos y morales; conteniendo por ello, dentro de sí, la esencia de la dignidad de lo humano.

Considerando lo expuesto, desde el marco de la psicología filosófica, se concibe al ser humano como un ser de naturaleza, tanto física como metafísica al asumir alma y espíritu como entidades metafísicas; toda vez que estas no pueden ser percibidas por los sentidos ni sometidas a observación y/o experimentación alguna en un laboratorio científico. Consideraciones en las que se debe reparar, especialmente por la importancia del retorno de la psicología a las raíces profundas de la filosofía y con ello a su objeto original de estudio; en la medida que el tema de la autognosis unida a la eudaimonia resultan cruciales para el desarrollo y realización integral del ser humano.

En efecto, Schopenhauer (2013) desarrolla el concepto del «hombre como animal metafísico». Afirma que ningún ser, a excepción del humano, es capaz de asombrarse frente a su propia existencia, y de cuestionarse acerca de su naturaleza al observar que otras personas cercanas a él mueren.

Su asombro es más serio en cuanto que aquí por primera vez, se halla frente a la conciencia de la muerte ... A partir de esta constatación y de este asombro surge la necesidad, metafísica que es propia solamente del hombre: él es en consecuencia un animal metafísico. (Schopenhauer, 2013, II, p. 17)

Esta necesidad metafísica expresa la urgencia que el hombre tiene de saber si existe algo más, e incluso diferente, de aquello que conoce empíricamente y que juzga gracias a la razón aspectos que en términos kantianos y schopenhauerianos, no sea representación. «Queremos conocer el significado de aquella representación, nos preguntamos acerca de si este mundo no es más que representación ... o si es algo más, y si es así, qué es ese algo más» (Schopenhauer, 2013, I, p. 17). Al igual que Schopenhauer, Kant (2019) se refiere a la necesidad metafísica del hombre como disposición natural del ser humano metaphysica naturalis: 
En efecto, la razón humana avanza inconteniblemente hacia esas cuestiones, sin que sea solo la vanidad de saber mucho quien la mueve a hacerlo. La propia necesidad la impulsa hacia unas preguntas que no pueden ser respondidas ni mediante el uso empírico de la razón ni mediante los principios derivados de tal uso. (p. B21)

Es evidente que para Schopenhauer y Kant este hecho no necesita de comprobación alguna. Toda vez que el hombre lleva dentro de sí una necesidad metafísica, dada la constante evidencia de que el hombre tiende permanentemente a plantearse preguntas, que van más allá de lo que él pueda percibir y comprender por medio de los sentidos y que considera de mayor importancia que aquello que percibe, de ahí la naturaleza metafísica y trascendental de las ideas; precisamente, a partir de esa necesidad metafísica, se da el nacimiento de las religiones y de los sistemas filosóficos con el fin de dar y encontrar respuestas a tan importantes inquietudes planteadas por la misma naturaleza del alma espiritual, propia del ser humano, unida a su facultad y necesidad de discernir y saber.

Con el propósito de encontrar la relación y diferencias etimológicas existentes entre conocimiento, sabiduría y autoconocimiento se observa que la sabiduría se encuentra íntimamente ligada con la filosofía en la medida que filosofía significa amor a la sabiduría. Se infiere que el ser humano nunca posee de manera perfecta la compresión del saber definitivo del todo, que esta posibilidad se encuentra contenida dentro de la sabiduría en la medida que el ser humano lucha siempre anhelante por llegar a ella teniendo en cuenta que, según su definición real, filosofía es aquel saber de la razón humana que penetrando hasta las últimas razones, investiga la realidad total especialmente del ser y el deber propio del hombre. Tal como lo refiere con toda autoridad Aristóteles, el padre de la psicología universal:

Todos los hombres están ansiosos de saber; es decir, que el deseo de saber es innato. Manifiéstese este ya en el niño, en los por qué y los cómo que no cesa de formular. Ese deseo es el principio de las ciencias, cuya principal finalidad no es dar al hombre medios de obrar sobre la naturaleza sino, en primer lugar, satisfacer su natural curiosidad. Si el deseo de saber es tan esencial al hombre, 
debe ser universal en el tiempo y en el espacio. Y esto es lo que nos enseña la historia. No hay pueblo, por retrasado que esté, en el que no se manifieste esta natural inclinación del espíritu, y es, por tanto, tan antigua como la humanidad. (Aristóteles, 1998, metafísica I, c. II)

Al relacionar Aristóteles la ansiedad con el deseo innato de saber en el ser humano, como algo esencial y universal en el tiempo y en el espacio, apoyándose en lo que dice la historia, asumida esta como experiencia y devenir, nos obliga a esforzarnos por entender el contenido de lo mencionado por Aristóteles en el sentido amplio y estricto en su contexto y significado; empezando por advertir la diferencia existente entre los verbos saber y conocer, de modo tal que el tenerlo en cuenta, otorga mayor sentido y fuerza a lo indicado por Aristóteles al atribuir a todo hombre, entendido como ser humano en cuanto género el deseo innato de saber; verbo que denota sabiduría, la cual al ser vinculada con el principio de las ciencias, coloca tanto implícita como explícitamente al conocimiento y a la ciencia, en la medida que estas últimas son desarrolladas por el ser humano anhelante por saber, en una condición de subordinación ante la sabiduría.

De esta conclusión, se desprende la afirmación: no puede haber psicología ni autoconocimiento sin filosofía. Afirmación que adquiere sentido en la medida que la psicología se gesta, forma, nace y permanece en el centro mismo del corazón de la filosofía, y en tanto el ser humano está llamado a manifestarse como un ser eminentemente filosófico desde el momento en que se plantea preguntas relacionadas con temas que van mucho más allá del mundo percibido por los sentidos. Encontrándose dentro de ellos otros igualmente trascendentales e importantes, tales como el sentido de la existencia y la felicidad. Temas que la psicología contemporánea se encuentra imposibilitada de abordar, al atribuirle a los mismos correspondencia de dominios propios de la filosofía, considerando que sus contenidos pertenecen al campo de la metafísica.

Con relación a ello, surge la pregunta: ¿acaso el alma humana, objeto único y genuino de estudio de la psicología humana desde sus orígenes, no requiere ser atendida en sus necesidades metafísicas? Esta observación debe inducir a un análisis abierto, sereno, constructivo y comprometido con el desarrollo integral del ser humano, máxime si se toma como indicador manifiesto la 
presencia recurrente del psicologismo en la filosofía. Lo cual llena de sentido dicha afirmación al considerar a Aristóteles como el verdadero padre de la psicología universal, ya que fue quien trató el tema del alma humana, así como las propiedades, facultades y manifestaciones de las mismas como nadie lo ha hecho en la historia de la filosofía occidental, dada la gran profundidad y dominio otorgado a la ética y al sentido existencial.

De acuerdo a lo planteado, y a la postura neoecléctica desarrollada en el presente trabajo, se reconoce y otorga a Aristóteles, merecidamente, la paternidad de la psicología neohumanista, la cual se encuentra en proceso de consolidación y se presenta en este artículo. La misma que la autora de este trabajo viene aplicando y desarrollando desde hace más de 40 años como psicóloga, mediante el permanente ejercicio de la psicología en prácticas de orientación y trabajos de investigación en los que se concibe al ser humano, desde entonces, como una unidad tridimensional, compuesta por elementos de naturaleza física y metafísica al mismo tiempo: cuerpo, alma y espíritu. Elementos que, al interactuar como unidad tridimensional, influyen entre sí $y$, por ende, en el desarrollo integral de la naturaleza humana, que se distingue del animal propiamente dicho por su condición de ser racional. El hacer uso del lenguaje como medio de expresión y comunicación, determina y presenta al ser humano como un ser eminentemente social, filosófico y teísta; manifestaciones que se expresan y constituyen en características connaturales a la naturaleza humana. De ahí la importancia de tomar conciencia en la necesidad que la psicología y la filosofía contemporánea regresen a sus orígenes, entendidas estas como sus raíces.

Demanda claramente justificada y expresada por Leuridan (2019):

La filosofía no es una disciplina universitaria o una crítica permanente infructuosa. Erudición sin presencia de sentido no basta. Un espíritu crítico solo ayuda a eliminar los errores del pasado. Es más importante preguntarnos por las dimensiones profundas de las grandes interrogantes existenciales que siempre formaron parte del corazón de la filosofía. ¿Cuál es el sentido de la vida, que son los ideales, la conciencia de obligación del hombre, las motivaciones, las normas y como se manifiesta la necesidad de la ética en la problemática del mundo actual? No se trata de analizar 
términos sino de dar conceptos que orienten a una vida. La cultura de un pueblo no es solamente ciencia, tecnología, literatura, pintura música, canto, baile, etc., sino también y fundamentalmente el respeto entre las personas, la ética. Necesitamos de los demás para poder entendernos a nosotros mismos y sentirnos realizados. Vemos entonces que la ética es el eje central de la vida, lo que le da sentido a la existencia. (pp. 21-22)

Por consiguiente, autognosis y eudaimonía van de la mano teniendo a la ética como punto de encuentro.

\section{El autoconocimiento como asignatura pendiente de la psicología}

No resulta complicado comprender que hablar de psicología implica remontarse a los siglos VI y $\mathrm{V}$ a. C., inicios del pensamiento racional en el mundo griego. Es importante remarcar que etimológicamente el término psicología lo componen dos voces griegas psique (alma) y logos (ciencia, estudio o tratado). Sus respectivos significados indican que la psicología es la ciencia que se encarga del estudio o tratado del alma; lo que adquiere gran relevancia al relacionarla con las llamadas ciencias humanas. Toda vez que, a partir de ello, podemos referirnos con propiedad a una psicología humana, cuyo objeto de estudio está llamado a ser el alma humana, principio y fundamento de la naturaleza vital del ser humano, la misma que se distingue del alma de los animales por su capacidad intelectiva racional, con potencialidades latentes aún no desarrolladas por el ser humano de hoy. Según Aristóteles:

Por naturaleza, los animales nacen dotados de sensación; pero esta no engendra en algunos la memoria, mientras que en otros sí. $Y$ por eso estos son más prudentes y aptos para aprender que los que no pueden recordar ... los demás animales viven con imágenes y recuerdos, y participan poco de la experiencia. Pero el género humano dispone del arte y del razonamiento. Y del recuerdo nace para los hombres la experiencia, pues muchos recuerdos la misma cosa llegan a constituir una experiencia. Y la experiencia parece, en cierto modo, semejante a la ciencia y el arte, pero la ciencia y el arte llegan a los hombres a través de la experiencia. (Aristóteles, 1998, Met. I.1, 980a 27-981a 3) 
Cuando Aristóteles utiliza la frase el hombre es un animal racional en concordancia con su teoría «El hombre es un animal político», lo hace tanto implícita como explícitamente por la pertenencia de este al reino animal; lo que se puede advertir con mayor precisión cuando Aristóteles ubica al ser humano con el resto de los vivientes en una escala natural (scala naturale): «los entes inanimados (minerales), las plantas (vegetales), los animales, el hombre. El hombre es, pues, un animal, pero un animal superior al resto de ellos» (Aristóteles, 1983, cap. 3, es. 414b 17 ss).

Consideraciones que se plantean como indispensables de ser tomadas en cuenta, en la medida que el tema a tratar tiene como propósito ofrecer una nueva vía de apertura y análisis a una asignatura como el autoconocimiento, que está pendiente de ser debidamente desarrollada desde hace más de 2400 años.

Desde otra perspectiva, Sócrates, uno de los padres de la filosofía universal, dejó como gran legado al ser humano, la tarea de seguir trabajando en el desarrollo de una mejor comprensión de la autognosis dentro del quehacer filosófico y mediante la máxima délfica nosce te ipsum:

Te advierto quien quiera que fueres, iOh; tú que deseas sondear los Arcanos de la naturaleza, que, si no hallas dentro de ti mismo aquello que buscas, itampoco podrás hallarlo fuera! Si tú ignoras las excelencias de tu propia casa ¿Cómo pretendes encontrar otras excelencias? En ti se halla oculto, el tesoro de los tesoros. «iHombre conócete a ti mismo y conocerás a Dios y el universo del Qué formas parte!». (como se citó en Martínez, 2014)

Que se entiende a partir de la filosofía, madre de todas ciencias; la cual denota asimismo amor por la sabiduría. En este contexto, no puede haber, psicología sin filosofía, ni filosofía sin psicología; en cuanto la psicología como ciencia humana, se gesta, nace y desarrolla, en sus orígenes como rama de la filosofía.

Es decir, se determina su objeto de estudio en la etapa antropológica de la filosofía clásica. En la actualidad, es necesario reconocer que las ciencias humanas colocan al ser humano dentro de diferentes campos de estudio, que 
se diferencian estas ciencias entre sí por los diferentes ámbitos de interés, observación, enfoques y objetivos con relación al estudio del ser humano; y que genera variadas interpretaciones en el estudio y comprensión de este, induciendo a las ciencias humanas, en la gran mayoría de los casos, a entremezclarse y contraponerse. Interpretaciones variadas de grandes impedimentos en la psicología humana para lograr un concepto integral sobre la naturaleza humana. Aspecto que influye radicalmente en la imposibilidad de construir un concepto sólido y unitario en la definición y, por ende, percepción del ser humano.

Por lo mencionado y, para efectos del autoconocimiento, es necesario concebir al ser humano como una unidad psico-biológica-espiritual; eminentemente filosófica, social y teísta; independientemente de la religión o posición que se tenga sobre ella. Más aún, si se considera que el ser humano es por naturaleza un ser eminentemente filosófico, debido a la manera cómo piensa, siente, vive, actúa y se proyecta en las diferentes etapas de su vida, encierra el fiel reflejo de su genuina actitud filosófica en acción, y en cuanto la misma deviene en la construcción de su propia filosofía de vida, en la que se traduce la forma como este viene enfrentando y procesando las diferentes vivencias y experiencias a lo largo de su existencia. Al respecto Popper (1994) afirma:

Todos los hombres y mujeres son filósofos; si no son conscientes de tener problemas filosóficos, en cualquier caso, tienen prejuicios filosóficos. La mayoría de estos son teorías que dan por supuestas: Teorías que han absorbido de su entorno intelectual o en la tradición; dado que pocas de estas teorías se sostienen de forma consciente, son prejuicios en el sentido de que se sustentan sin examen crítico, aun cuando fueran tener una gran importancia para las acciones prácticas de las personas, y de su vida toda. (p. 231)

Este proceso se inicia en el mismo instante en que el ser humano toma conciencia de estar vivo y, con ello, del hecho de su existencia, que lo lleva a plantearse desde muy temprana edad preguntas profundamente elementales y trascendentales: ¿quién soy?, ¿de dónde vengo?, ¿hacia dónde voy?, ¿qué hago aquí?, ¿quién me creo, e hizo todo lo que me rodea?; ¿Dios existe?, y si 
existe ¿dónde está?, ¿qué es la vida?, ¿por qué se muere la gente?, ¿cómo es la muerte?, ¿cuál es el sentido de la existencia?, ¿qué es la felicidad?, y ¿qué puedo hacer para lograrla? La capacidad de plantearse dichas preguntas, como resultado de acceder al ejercicio de la reflexiva y el análisis, constituye una característica que solo posee el ser humano, el mismo que al comprenderlo despierta a la capacidad de intuir que está dotado de muchas virtudes y capacidades aún no manifiestas.

En consecuencia, dar respuesta a la pregunta sobre el sentido de la existencia desde la perspectiva del ser humano, unida a la autognosis, debe conducir a la revisión de los logros alcanzados por la psicología a lo largo de su proceso histórico, partiendo desde sus orígenes hasta llegar a la actualidad y en cuanto ciencia humana, a la luz de los principios de la ciencia contemporánea e influencia de la filosofía en ella.

\section{El alma humana como objeto de estudio insustituible de la psicología en cuanto ciencia humana}

Vincular a la psicología con el autoconocimiento es remontarse al período antropológico o socrático. Presentándose hoy por hoy el conócete a ti mismo y conocerás a los demás, no tan solo como el imperativo categórico por excelencia, desde aquellos tiempos, sino además como el reto pendiente más importante y urgente a resolver en la historia de la humanidad.

El desarrollo de este punto puede generar reacciones de rechazo o de interés. En el primer caso, como una provocación abierta hacía los principios fundamentales del positivismo científico, y en el segundo caso, como el inicio de una serie de oportunidades para encontrar, por medio de serias y profundas reflexiones, pautas e inquietudes jamás manifiestas dentro la psicología contemporánea, ya que estas, desde su ingreso al universo del positivismo científico, les resultan extrañas y esquivas; en principio y específicamente, el autoconocimiento y alma humana.

Precisamente, el alma humana es la que define, etimológicamente el sentido u objeto de estudio de la psicología como tal, en cuanto ciencia humana. Pero, jamás ha sido incluida en los aspectos a estudiar ni a considerar; salvo, como requisito obligado al inicio de la primera clase del curso de introducción a la 
psicología y para efectos de justificar etimológicamente las raíces del significado de su nombre. Por lo tanto, es el momento de plantear una serie de reflexiones con relación a lo mencionado.

¿Es posible acaso, denominar psicología a una ciencia humana que, en su legítimo afán de ser reconocida como ciencia, se ha visto obligada a abandonar su original objeto de estudio, claramente definido y determinado en su definición etimológica, con el fin de ser reconocida como ciencia? Y, en congruencia con la reflexión anterior ise puede llamar psicología a una rama del conocimiento que no se encuentra en condiciones de determinar y mucho menos definir los elementos que conforman la estructura de la naturaleza del ser humano? Y, ¿hasta qué punto le es realmente posible a la psicología contemporánea referirse al ser humano, sin encontrarse en la capacidad de abordar con total independencia y conocimiento de causa, los elementos estructurales que conforman la naturaleza humana unida a la forma como estos elementos interactúan, influyen y se relacionan entre sí?

En función de lo preguntado, es indispensable tomar en consideración que la «psicología significa etimológicamente ciencia del alma o de lo anímico (Psíquico). Significado real ordinario que ha variado reiteradas veces» (Brugger, 2005 , p. 452). En consecuencia, el objeto de estudio que le corresponde a la ciencia humana que se autodenomina psicología, se encuentra claramente determinado por su definición y significado etimológico; es decir, es el alma humana y no otro. Esta apreciación es una actitud seria y responsable que muestra el origen de los problemas que viene presentando desde sus inicios la psicología; cuya finalidad, frente a la falta de claridad y consistencia en la determinación y práctica de su objeto de estudio, es tener la capacidad de superarlos.

Al respecto, Jolivet sostiene que «definir la psicología equivale a decir cuál es su objeto propio y formal. Pero esto no es tan fácil como muchos pudieran pensar. En efecto, dos psicologías se ofrecen a nuestra consideración, llamadas respectivamente experimental y racional, y es preciso saber si se las debe hacer entrar en una definición común y considerarlas como dos partes, una subordinada a la otra, de una ciencia única, o si hay que dar exclusivamente a una o a la otra de estas disciplinas el nombre de psicología. En la discusión de estos problemas, que pretenden precisar el objeto propio que se ha de 
señalar a la psicología, nos será dado tropezar con numerosas y diversas concepciones que tendremos que estudiar y criticar» Jolivet (1956, T. II, p. 10).

En concordancia con lo señalado por Jolivet (1956), sobre la necesidad de determinar la independencia e interdependencia de las dos psicologías, en este estudio se suma una nueva reflexión a las tres reflexiones pendientes por desarrollar en el punto anterior, la cual exige ser analizada de forma inmediata y mediante la siguiente interrogante: ies posible llevar a experimentación, dentro del contexto de la investigación científica, algo que previamente no se ha establecido, conceptualizado y determinado con la serenidad y responsabilidad que el caso requiere durante el proceso analítico propio de la racionalidad?

La respuesta a dicha reflexión resulta negativa toda vez que aceptar lo contrario equivaldría a aceptar, dentro de este contexto, la validez de la existencia de la teoría sin la práctica. Sin perjuicio de lo anteriormente mencionado, cabe considerar que Jolivet al igual que Brugger reconocen a la psicología por su definición etimológica como ciencia del alma.

Podemos conservar sin inconveniente esta definición con tal que se le deje toda su generalidad y que comprendamos que el alma no puede ser conocida sino en y por las diversas manifestaciones de su actividad. La Psicología será, pues necesariamente el estudio empírico de los fenómenos psíquicos. Este estudio ha recibido el nombre de psicología experimental descriptiva. Más adelante nos preguntaremos si semejante estudio puede ser autónomo y también cuál es su objeto para seguir siendo siempre una disciplina positiva. (Jolivet, 1956, T. II, p. 10)

En la misma línea de reflexión, debido al estudio de los métodos positivos, se puede afirmar que la ciencia positiva de los fenómenos psíquicos no agotará el objeto total de la psicología; del mismo modo que la determinación de las leyes físicas no agota el conocimiento de las cosas de la naturaleza y del mundo, si bien es cierto, la filosofía pretende llegar al ser mismo que manifiestan los fenómenos y las leyes que lo rigen. Quedará, pues, para la psicología una tarea ulterior que consistirá en establecer, a partir de la experiencia, la existencia y la naturaleza del principio; primero, de los 
fenómenos psíquicos que es el objeto propio de lo que se llama la psicología racional o psicología filosófica.

Ante lo cual, en principio y por principio, desde la perspectiva del presente estudio, corresponde reparar sobre la compatibilidad de la naturaleza metafísica del alma humana, con la coherencia de los fundamentos y principios del positivismo científico en la aplicación y concepción de su método. Con relación a ello, Bunge marca en la filosofía contemporánea un derrotero significativo a considerar y, por ende, a evaluar sobre el consenso con respecto al objeto de estudio de la psicología (IntraMed, 2013).

Se aprecia -como en otras disciplinas- una falta de consenso acerca del verdadero objeto de la psicología. De esa forma se puede definir como el estudio de la conciencia o estudio de la conducta manifiesta. La mayor importancia de la cuestión de objeto en comparación con otras ciencias radica en el carácter transitorio del estudio protocientífico a científico (Bunge y Ardila, 2012).

Las afirmaciones de Bunge, conducen a preguntarse, de manera seria y responsable (dentro del marco de la psicología filosófica, la cual no debe confundirse de forma alguna con la filosofía de la psicología): iserá acaso, que un aspecto importante a considerar en la cuestión del objeto de la psicología, en comparación con otras ciencias, radica en el hecho que al haberle extirpado la esencia de su significado etimológico, la han privado del sentido propio de su existencia y, por lo tanto, de su razón de ser, colocándola de esta forma sobre una ruta sin piso y sin rumbo específico?

La respuesta afirmativa a dicha reflexión es previsible, en la medida que la misma, permitirá articularla con las conclusiones de las reflexiones pendientes a resolver (planteadas anteriormente). Estas, se encuentran íntimamente relacionadas con el contenido de lo que se señaló en este trabajo al citar a Bunge; cuando al referirse a la falta de consenso sobre el objeto de estudio de la psicología, indica que la misma podría definirse como el estudio de la conciencia o estudio de la conducta manifiesta.

Visto de esta forma, a la luz de la seriedad e importancia que encierra tradicionalmente la esencia del significado etimológico en el universo de las 
ciencias del conocimiento, nos encontramos, desde la psicología filosófica, frente al reto de demostrar que la ciencia que ha venido asumiendo el nombre de psicología, dentro del universo de las ciencias humanas, no puede ser aceptada como tal; en cuanto no se encuentra en capacidad de definir el alma humana al ser esta en principio su único y auténtico objeto de estudio. Este hecho la inválida en la medida que se encuentra imposibilitada de desarrollarse a partir de la definición de su original objeto de estudio, ya que este no ha sido estudiado y mucho menos investigado como tal por la psicología en mención y en tanto no resulta impropio el tomar seriamente en consideración lo expuesto por Bunge. Lo cual induciría a preservar el verdadero y auténtico objeto de estudio de la psicología respetando su raíz etimológica.

Siguiendo lo manifestado por Bunge, referirse a la psicología como la ciencia que se centra en el estudio de la conciencia no sería lo indicado, en la medida que al tener a la conciencia como objeto de estudio, el nombre que le correspondería sería concienciología y no otro; dándose el mismo caso con el de la ciencia que se encarga del estudio de la conducta, sea esta manifiesta o reprimida, la cual se debería denominar conductología, debiendo aplicarse el mismo criterio a la definición actual de la psicología, la cual se atribuye el estudio de los procesos mentales. Siempre y cuando se preocupe por definir de antemano y con claridad lo que se debe entender por mente, liberando a la misma de haberla convertido en sinónimo de alma. Solo así podrá encontrarse en condiciones de constituirse en la ciencia de la mente, adquiriendo con ello la denominación de mentología propiamente dicha.

Conservando de esta forma la independencia y la pureza en las diferencias de los significados existentes, entre alma y mente; alma y conducta; $y$, alma y conciencia, sin perder de vista el objetivo común a alcanzar, lo que se traduce en convertirse en ramas complementarias de la psicología. Vale decir, se le atribuye como corresponde a esta última, la exclusividad y primacía del estudio del alma humana, en cuanto ciencia humana; orientándose con ello hacia el camino del autoconocimiento. Para tal fin, es necesario partir de la premisa que el concepto del alma humana, desarrollado tanto por Platón como Aristóteles, presentaron desde un inicio marcadas diferencias y similitudes entre sí. Diferencias y similitudes que hasta el momento no son debidamente confrontadas y mucho menos aceptadas ni comprendidas. 
Lo señalado son aspectos que vienen constituyéndose, sin lugar a duda, en el freno principal de la psicología como ciencia humana, para asumir con la solvencia y el conocimiento del caso la concepción del alma humana como su objeto de estudio dentro del universo de conocimiento científico. En función a ello, es conveniente tomar en consideración que la psicología es dueña de un largo pasado y una breve historia. Encontrándose dentro del contexto de esa breve historia el reto de hacerla florecer en su verdadera dimensión; para ello es necesario determinar la función que desempeña el alma humana en su interrelación dentro de la estructura de la naturaleza del ser humano al formar parte de esta.

Se presenta como imperativo categórico para la psicología propiamente dicha, la necesidad de retornar a sus raíces, con el fin de descifrar la riqueza oculta existente en los códigos de las diferencias y similitudes esgrimidas por Platón y Aristóteles con relación al alma humana; y así, poder ir al encuentro de la ruta de la autognosis. Hecho que obliga a reafirmar, una vez más, que no puede haber psicología sin filosofía.

A partir de lo expresado, corresponde prepararse para superar los problemas creados por el uso impropio del lenguaje al momento de definir y determinar con diáfana exactitud los objetos de estudio de las diferentes especialidades en el universo del conocimiento. Aspecto que al relacionarlo con la afirmación esgrimida por Mario Bunge, pareciera estar siendo abiertamente avalado por la epistemología.

En consecuencia, todas las consideraciones planteadas en estas reflexiones orientan a delinear el proyecto de una nueva ruta para el nacimiento de una psicología sólidamente articulada, con una filosofía y ciencia que unan esfuerzos para crecer unidas sobre una ruta coherentemente sostenida en el conocimiento de la naturaleza humana.

\section{Aspectos que vienen limitando el acceso del autoconocimiento en el ser humano contemporáneo}

Una de las grandes limitaciones que está llamado a superar el ser humano de todos los tiempos, en la forma que este tiene de conocer, pasa por liberarse de los paradigmas vigentes de su época. Para ello, tiene como punto de 
partida la teoría de los mundos de Platón, la misma que encuentra su punto de unión y equilibrio en el concepto del justo término medio aristotélico. El que aplicado al tema del autoconocimiento implica integrar en la naturaleza del ser humano la parte física y metafísica de la misma; percibiendo al ser humano como una unidad tridimensional compuesta de cuerpo, alma y espíritu. Manifestándose por ello como un ser eminentemente social, reflexivo y espiritual. Lo determina en él, las características propias de su naturaleza humana, por ende, su dignidad como tal. Establece, como bien lo demuestra Aristóteles, la marcada diferencia entre el ser humano y el animal como tal.

Bajo esta premisa, se identifica con toda claridad la influencia del positivismo científico de Auguste Comte, en la teoría del origen de las especies de Darwin (1859), la misma que sigue incidiendo en la forma distorsionada que el ser humano tiene de verse y percibirse así mismo, a los demás y al sentido de la existencia. Lo cual deviene en contraproducente tanto en el campo de la psicología experimental como en la proyección general de la misma, al haberse aceptado estudiar las manifestaciones del alma humana por medio de experimentos con animales, obligándonos a asumir con ello al ser humano como un ser que responde a estímulos y respuestas con indicadores neuroquímicos determinados por manuales de diagnósticos de trastornos mentales elaborados por la ciencia alejándose con ello de las manifestaciones propias y genuinas de la naturaleza del alma humana, ignorando con ello la dignidad del ser humano como tal.

Estos postulados conducen a reducir la inteligencia integral del ser humano a una inteligencia emocional, la misma que en tanto racional e instintiva se presenta como una gran incógnita a resolver; afirmación que realiza Paul Ekman en el programa Redes de la televisión española, quien es un psicólogo norteamericano darwinista, considerado uno de los expertos más notables en el conocimiento de las emociones y expresiones faciales universales. Frente a la pregunta ¿para qué sirve las emociones?, respondió que no lo sabía, puesto que él no las había creado, agregando que esta pregunta era muy difícil de responder, ya que lograr una respuesta para ello, implicaba preguntarse para qué y el porqué de su existencia; que estas eran unas preguntas que generalmente no se hacían los científicos (Bio Emoción, 2012). 
Un referente más es el diálogo protagonizado por la filósofa Victoria Camps y el psicólogo Mario Villegas, donde queda de manifiesto la gran importancia en desarrollar un vínculo adecuado entre la filosofía y la psicología para dar nuevos derroteros en aspectos trascendentales en el ser humano, entre ellos, temas como la razón, la libertad, la autonomía, los trastornos mentales, la moral, la ética y la felicidad (Herder Editorial, 2012).

Asimismo, se considera el aporte de Bunge, quien al desarrollar el tema sobre filosofía para médicos pone en manifiesto las grandes limitaciones propias del reduccionismo científico en las ciencias de la salud mental para abordar la salud del ser humano desde una perspectiva integral. Se refiere básicamente a la falta de solvencia en el rigor científico en investigaciones y metodologías de las disciplinas encargadas de la salud mental; las mismas que Bunge tiene a bien considerar como ciencias atrasadas en el universo de las pseudociencias, aseverando que ha llegado el momento en que la psiquiatría se haga científica (IntraMed, 2013).

En suma, el reto de la ciencia de la salud en general, comprometida con el bienestar del ser humano, pasa por que la ciencia conciba al ser humano desde la sanidad y no desde la enfermedad; investigando de forma seria y responsable el tema de la psicomatización, el estrés, el efecto placebo y la farmacodependencia; para ello, es necesario que el ser humano se encuentre a la altura de esta gran responsabilidad.

\section{Conclusiones}

Abordar el tema del autoconocimiento dentro del marco del pensamiento abierto de la psicología filosófica, refleja la imperiosa necesidad de que el ser humano -que se encuentra tanto detrás como frente a la ciencia, la filosofía y la tecnología- disponga de una predisposición coherente con el sentido de la vida, la salud, la existencia y el bien común del cual todos formamos parte, pasando por flexibilizar los esquemas conceptuales de los paradigmas vigentes.

Para ello, es necesario que recupere la confianza en su capacidad de desarrollar las potencialidades propias del ser individual que habita dentro de sí mismo y su dignidad como tal, mediante la práctica y fortalecimiento de la ética y la moral, base y fundamento de acceso a la autognosis. En tal 
sentido, el carácter teleológico del presente estudio, queda circunscrito en resaltar la importancia del autoconocimiento dentro del campo de la psicología para la realización integral del ser humano. Para lograrlo se requiere la construcción de una nueva visión del hombre de hoy, con acceso a todos los campos de las manifestaciones culturales, con el fin de entregar a la humanidad nuevas luces para acceder al tan ansiado camino del autoconocimiento sostenido.

En consecuencia, se resalta la importancia de instalar en la psicología contemporánea la necesidad de desarrollar un enfoque transdiciplinario basado en el autoconocimiento, donde la psicología retorne a sus raíces profundas de la filosofía, retomando su fortalecido objeto original de estudio; y que esté en contacto con los problemas de la humanidad para así trabajar por el bienestar integral del ser humano.

\section{Referencias}

Aristóteles. (1983). Acerca del alma [Trad. T. Calvo Martinez]. Editorial Gedros.

Aristóteles. (1998). Metafísica [Trad. V. García Yebra]. Editorial Gedros.

Bio Emoción. (2012, 24 de agosto). ¿Crear salud redes para que sirven las emociones? [Video, parte 1]. Youtube. https://www.youtube.com/watch?v=9m_-_S1yG0Y

Brugger, W. (2005). Tratado de filosofía. Editorial Herder.

Bunge, M. y Ardila, R. (2012). Filosofía de la psicología. Siglo XXI Editores.

Herder Editorial. (2012, 15 de mayo). Un diálogo entre filosofía y psicología [Video]. Youtube. https:/l www.youtube.com/watch?v=60qch_zm_8s

IntraMed. (2013, 24 de enero). Filosofía para médicos. Mario Bunge en IntraMed [Video]. Youtube. https:/l www.youtube.com/watch?v=LO83LJ70xVc

Jolivet, R. (1956). Tratado de Filosofía. Ediciones Carlos Lohlé.

Kant, I. (2019). Critica de la razón pura. Editorial Taurus.

Leuridan, J. (2019). El sentido de las dimensiones éticas de la vida. Fondo Editorial USMP.

Popper, K. (1994). En busca de un mundo mejor. Editorial Paidós.

Schopenhauer, A. (2013). El mundo como voluntad y representación. Alianza Editorial. 